\title{
The Effect of Education on Knowledge, Attitude and Practice of Sirjan School of Medical Sciences Staff Regarding the Use of Food Labels
}

Batool Farahbod

Food and drug administration, Sirjan School of Medical Sciences, Sirjan, Iran

Fatemeh Rahmati-Najarkolaei *Health Research Center, Lifestyle Institute, Baqiyatallah University of Medical Sciences, Tehran, Iran. (corresponding author):

Fatemeh_rahmati@bmsu.ac.ir

Mohadeseh Balvardi

Instructor of Biostatistics, Sirjan School of Medical Sciences, Sirjan, Iran

Zahra imani Goghary

Nursing \& midwifery department, Sirjan School of Medical Sciences, Sirjan, Iran

Fahimeh Farahbod

Food and drug administration, Sirjan School of Medical Sciences, Sirjan, Iran

Rahmat Allah Zeidabadi

Food and drug administration, Sirjan School of Medical Sciences, Sirjan, Iran

Received: 2020/05/8

Accepted: 2020/12/16

Doi: 10.52547/ijhehp.9.1.33

\begin{abstract}
Background and Objective: Education seems to be more effective in improving people's knowledge, their dietary patterns and healthier food choices. Therefore, this study was conducted to determine the effects of education programs on the consumers' knowledge, attitude and performance towards using food labels. Materials and Methods: The present cross-sectional study was performed on 250 employees of Sirjan University of Medical Sciences, Iran. The data collection tool was a self-administrated questionnaire which included 9 demographic information questions, 7 knowledge-related questions, 4 attitude questions, 5 performance questions and 5 comment questions about food labels and their characteristics. The education was in the form of lectures in the form of 2 sessions of 120 minutes with an interval of one week with group discussion, and participatory training. This study did not have a control group and had a before and after study design. 6 weeks after the training program, the questionnaires were completed again by the subjects.
\end{abstract}

Results: The age range of these employees was between 21 and 57 years and $85.6 \%$ of them were married. The results of this study showed that the mean score of knowledge before the training was $11.38 \pm 3.28$ which consequently increased to $20.92 \pm 2.42$ after the education. The mean attitude score changed from 29.48 \pm 5.43 to $30.31 \pm 4.79$; In addition, the mean performance score increased from $12.62 \pm 3.31$ to $17.88 \pm 2.15$. The results showed a significant difference between the mean scores of knowledge $P \quad 0.001$, attitude $P=0.03$ and performance $P$ 0.001 before and after the education.

Conclusion: Since there is a significant difference between the knowledge, attitude and performance scores of the Sirjan University of Medical Sciences' staff before and after the education, the use of direct education method on the subject of food labels is recommended.

Keywords: Food labels, Nutrition facts label, Knowledge, Attitude, Practice. Paper Type: Research Article.

Citation (Vancouver): Farahbod B, Rahmati-Najarkolaei F, Balvardi M, Imani Goghary Z, Farahbod F, Zeidabadi R. The Effect of Education on Knowledge, Attitude and Practice of Sirjan School of Medical Sciences Staff Regarding the Use of Food Labels. Iran J Health Educ Health Promot. Spring 2021;9(1): 33-44. [Persian]

Citation (APA): Farahbod B., Rahmati-Najarkolaei F., Balvardi M., Imani Goghary Z., Farahbod F., Zeidabadi R. The Effect of Education on Knowledge, Attitude and Practice of Sirjan School of Medical Sciences Staff Regarding the Use of Food Labels. Iranian Journal of Health Education \& Health Promotion., 9(1), 33-44 . [Persian] 


\section{تاثير آموزش بر دانش، نكرش و عملكرد كاركنان دانشكده علوم يزشكى سيرجان بيرامون \\ استفاده از برجسبهاى مواد غذايى}

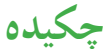

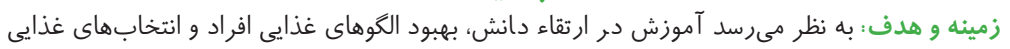

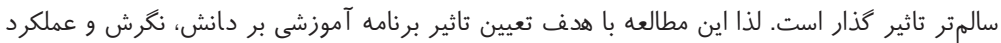

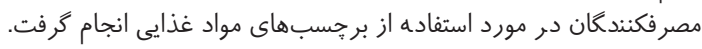

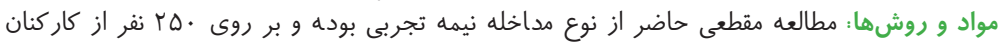

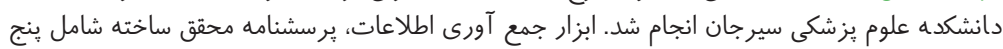

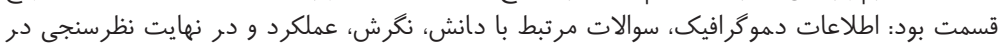

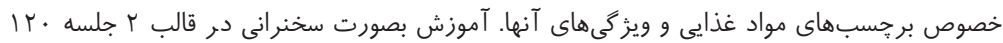

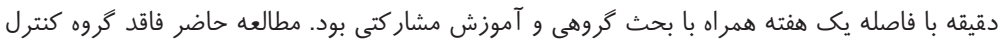

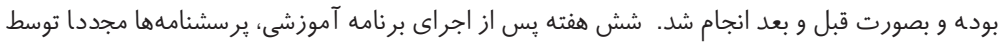
نمونه ها تكميل گرديد.

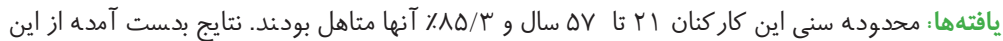

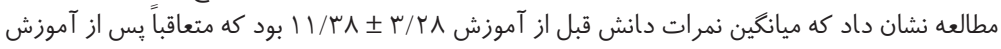

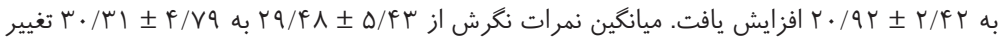

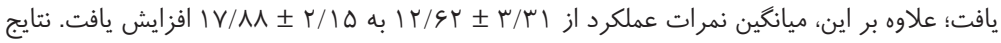

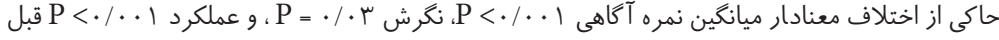

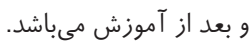

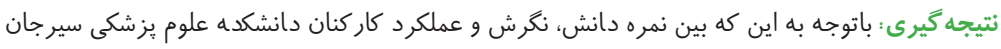

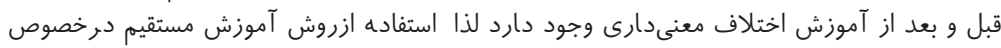

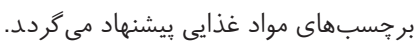

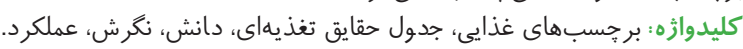

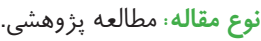

4 استناد (ونكوور): فرهبد ب، رحمتى نجار كلائى ف، بلوردى م، ايمانى گوغرى ز، فرهبد ف، زيدآبادى سي

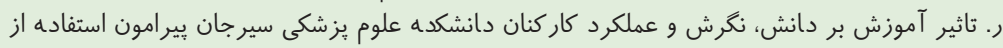

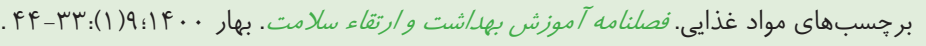

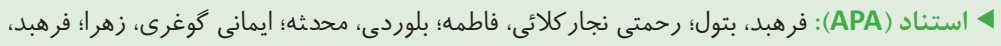

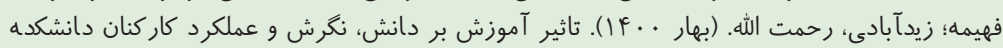

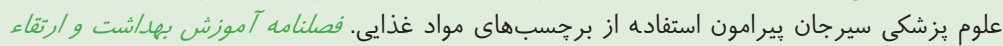

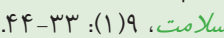

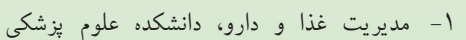
سير جان، سير جان، ايران

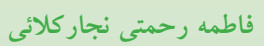

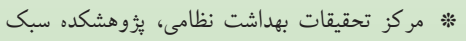

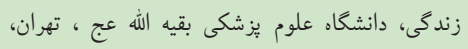
ايران. (نويسنده مسئول). Fatemeh_rahmati@bmsu.ac.ir

$$
\begin{aligned}
& \text { محدثثله بلوردى } \\
& \text { مربى آمارزيستى، دانشكده علوم يز شكى سيرجان، } \\
& \text { سير جان، ايران }
\end{aligned}
$$

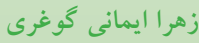
مديريت غذا و دارو، دانشكده علوم يزشكى سيرجان،

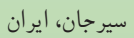
رحمت الله زيدآبادى سير ئرن مديريت غذا و دارو، دانشكده علوم بيزشكى سيرجان، رئري سيرجان، ايران

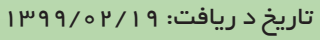

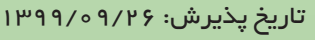


استفاده از برجسبهاى تغذيهاى مواد غذايى با مصرف كل جربى،

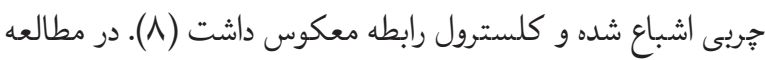
اى كه در دانشجويان دوره متوسطه در Ghana انجام شد مشخص

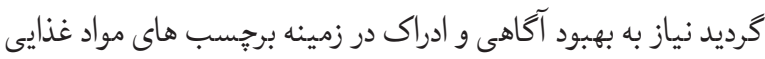

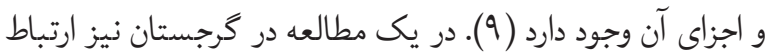

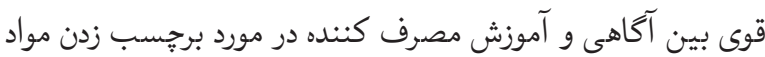

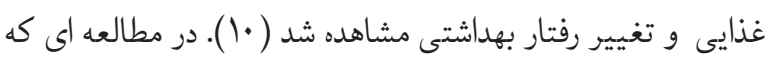

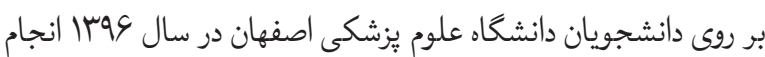

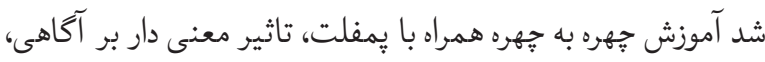

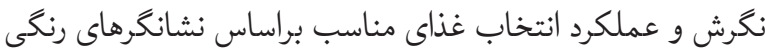

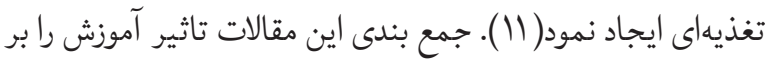
انتخاب غذاى سالم تر نشان مىدهد. نتايج مطالعات مختلف بيانكر اينست كه با وجود اينكه مصرف كنندگان بر لزوم استفاده از غذاهاى سالم و مغذى تاكيد دارند اما همجنان اولين معيارهاى انتخاب غذايى آنان طعم و مزه غذا،

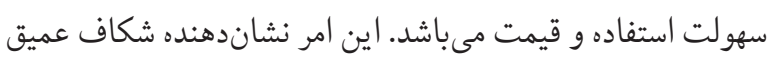
ميان نكرش و رفتار مصرف كنند گان است. بنابر اين مصرف كنند گان براى انتخاب درست نياز به شفافسازى و اطلاعات قابل اعتماد

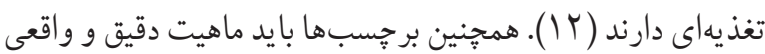

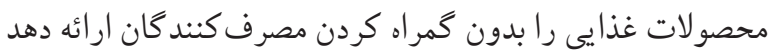
(Y). بنابر شواهد تعدادى از مصرف كنند كان قادر به محاسبه و

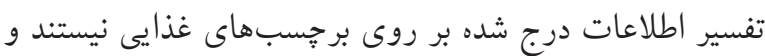

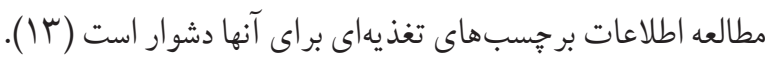

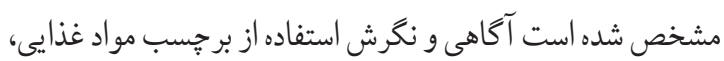

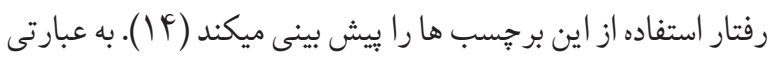

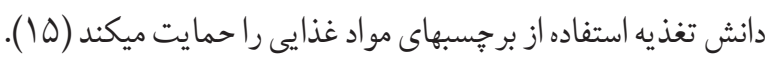

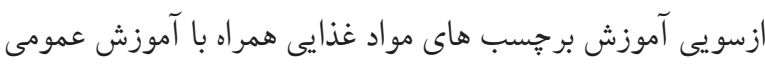

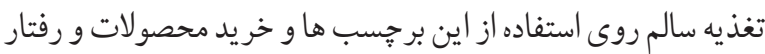
غذايى تاثير مثبتى دارد (4). لذا اين مطالعه با هدف ارزيابى تاثير

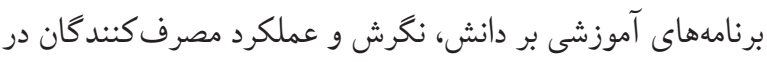

شيوع بيمارىهاى غيرواگير مربوط به تغذيه، از جمله جاقى، ديابت و سندرم متابوليك كه عامل · V درصد مرك و مير در سراسر جهان

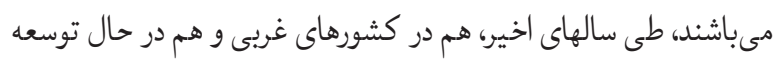
به سرعت در حال افزايش است. از آنجا كه هزينههاى سالانه درمان

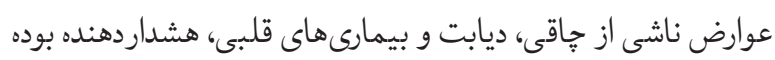

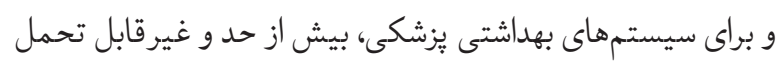

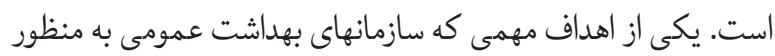

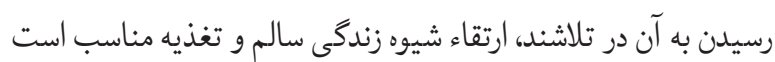

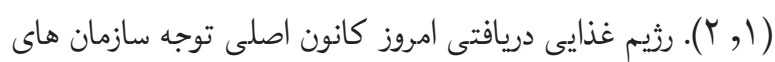

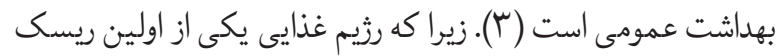

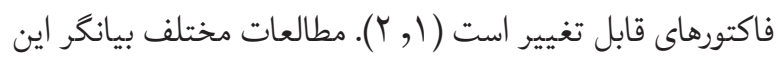
واقعيت است كه نكرش مصرف كنندگان نسبت به غذاها و عادات غذايى مناسب به سرعت در حال افزايش است و مصرف كنندگان

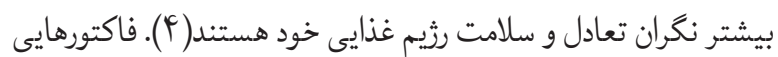
نظير عوامل اقتصادى (درآمد خانوار و قيمت كالاها)، اجتماعى و و وند دموگرافيك، باور مصرف كننده، شيوه زندكى و دغدغه هاى مريوط به سلامت و ايمنى ماده غذايى از عوامل متعدد موثر بر انتخاب مواد

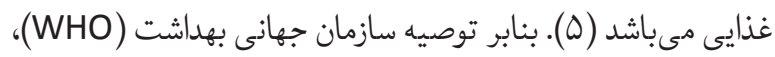

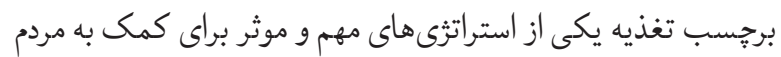

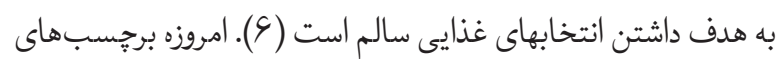
غذايى ابزار مهمى براى فراهم كردن اطلاعات مناسب در مورد ارزش تغذيهاى محصولات مختلف از جمله محتوى كالرى، مقدار و نوع

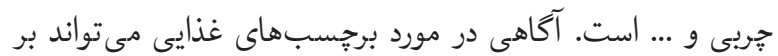

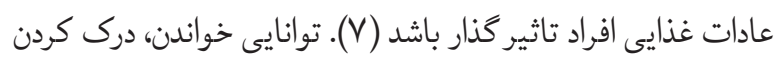
و استفاده صحيح از برجسبهاى غذايى بسيار مهم است. با توجه به ارتباط بين بيمارى مزمن و عادات تغذيهاى نامناسب، استفاده از برجسب هاى غذايى و بايبندى به توصيه هاى رزيمى براى افراد مبتلا

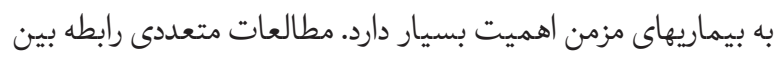

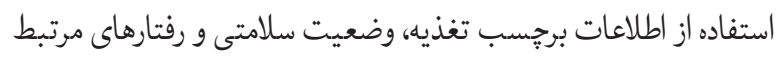
را با نتايج متفاوت بررسى كردهاند. به عنوان مثال، در يك مطالعه، 
شغل، درآمد خانوار و درآمد اختصاص يافته به خوراك در ماه بود.

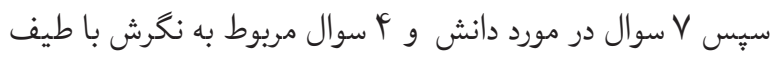

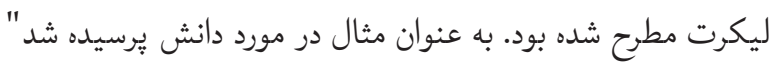

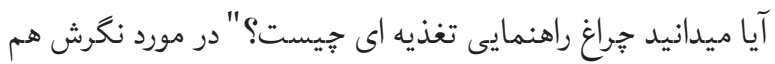

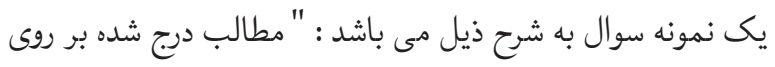
برجسب هاى مواد غذايى به راحتى قابل فهم هستند".

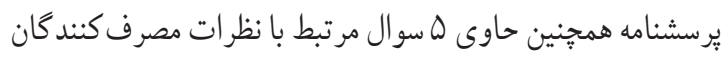

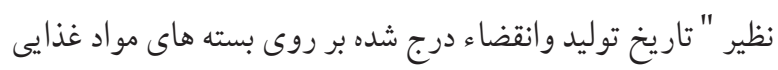

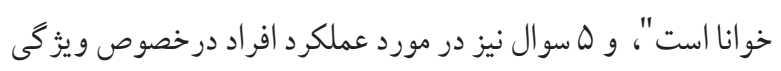

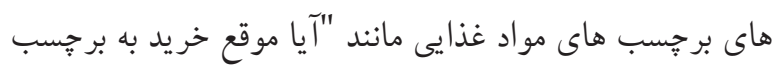

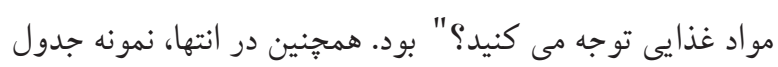

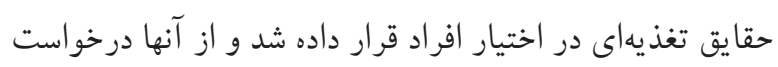

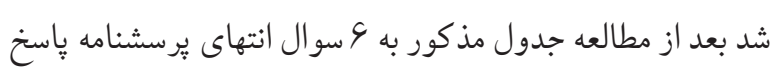
دهند. بدين ترتيب جُخونكى خواندن و محاسبه و تفسير برجسب غذايى نمونه مورد بررسى قرار خرفت.

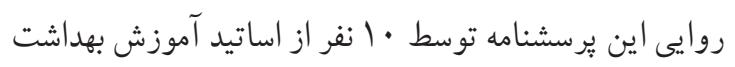

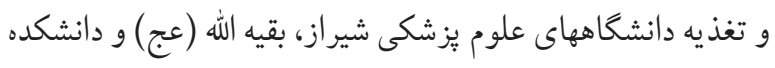

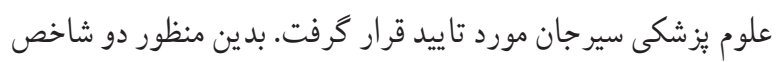
CVR و CVI

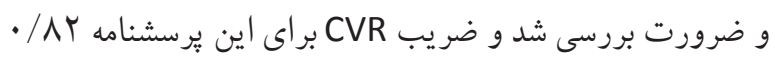

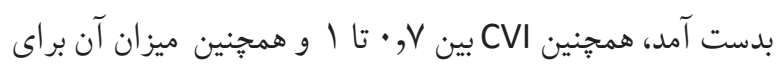
هر بخش از V9, · ب بيشتر بود.

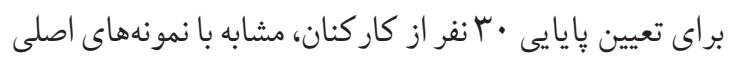

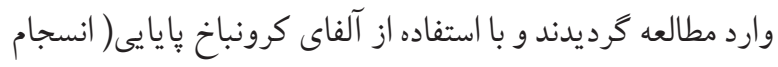

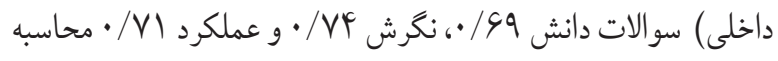

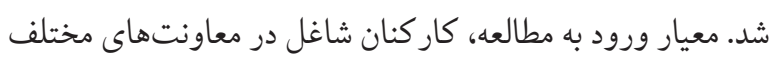

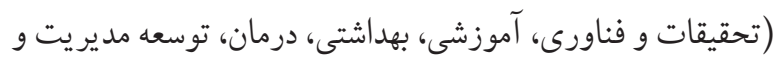

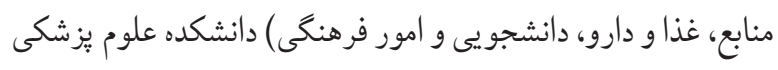
سيرجان و معيارهاى خروج از مطالعه شامل: عدم رضايت به ادامه

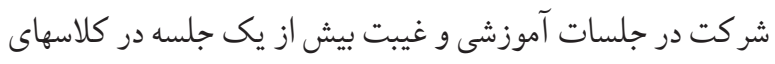

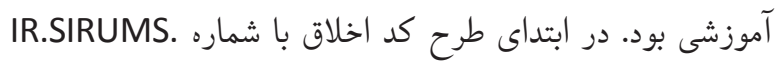

مورد برجّب هُهاى مو اد غذايى انجام كرفت. با توجه به اينكه كاركنان

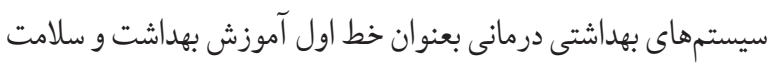

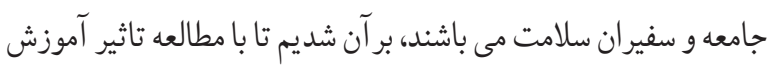

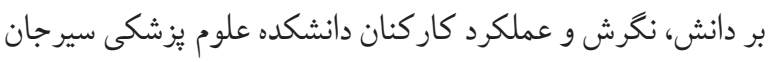

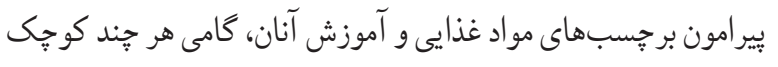
در جهت ارتقاء سطح سلامت جامعه برداريم.

مواد و روش ها اين تحقيق يك يُوهش نيمه تجربى و از نوع مقطعى است كه در

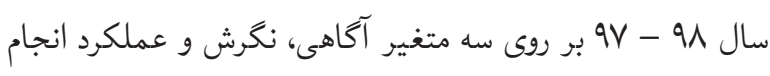
كرفت. روش انجام آن به اين نحو بود كه محققين يك موقعيت خاص را كه همانا اجراى برنامههاى آموزشى است، ايجاد نموده و

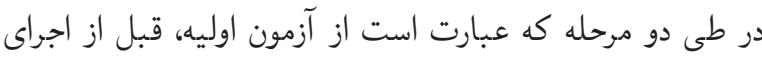
برنامه آموزشى و آزمون ثانويه بعد از اجراى برنامه آموزشى بدون

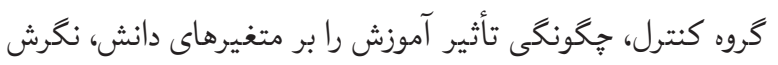

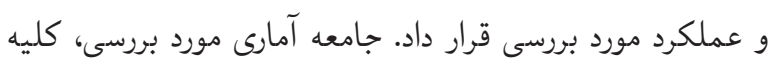

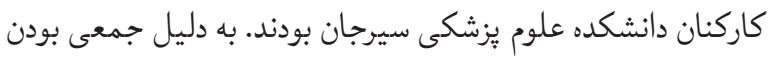

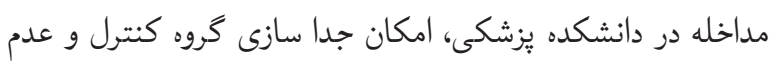
تاثير مداخله روى گروه كنترل وجود نداشت لذا طراحى اين مطالعه به درانه

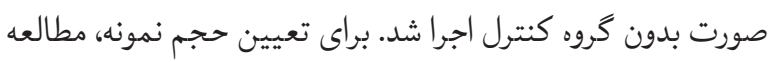

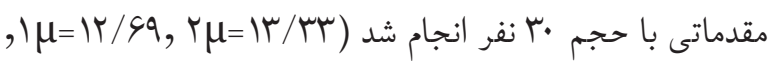

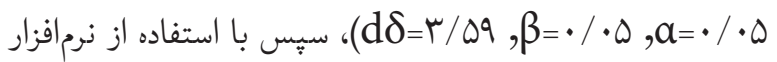
NCSS حجم نمونه تعداد YYN

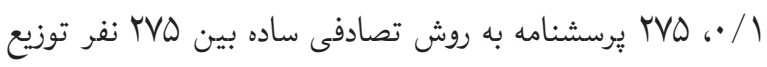

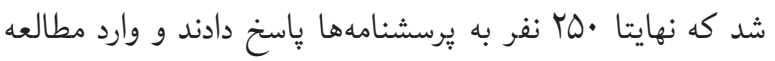

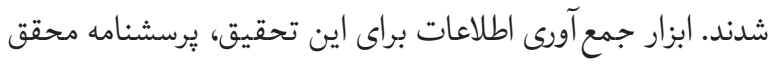

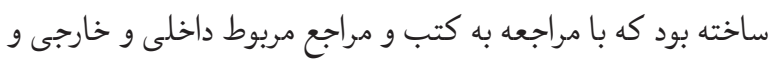
برخى تحقيقاتى كه در اين زمينه انجام شده (يرسشنامه طرح بازٔن و

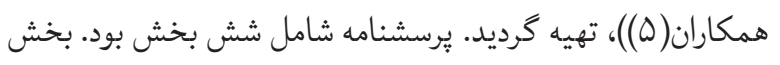

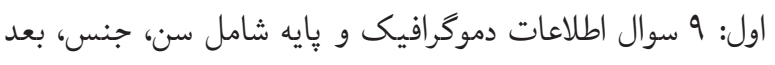
خانوار، تعداد افراد شاغل در خانوار، وضعيت تأهل، ميزان تحصيلات، 
rV
سنى افراد

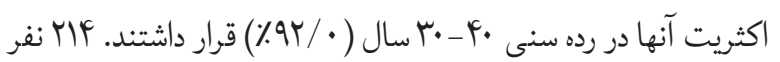

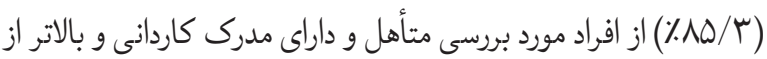

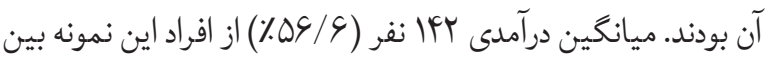

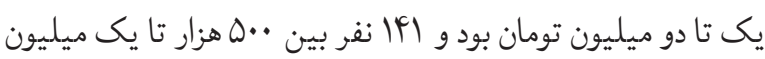

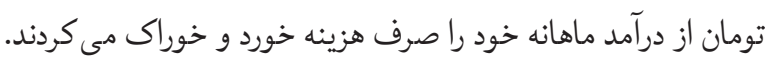

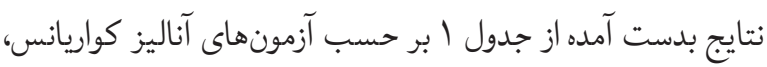

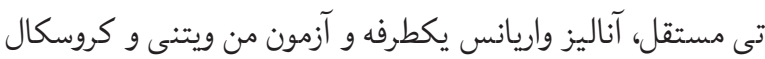
واليس نشان مى دهد ارتباط هيجگكدام از متغيرهاى دموكرافيك بر نمرات

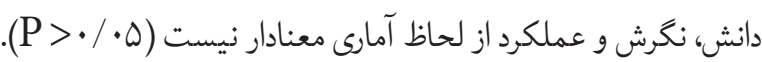

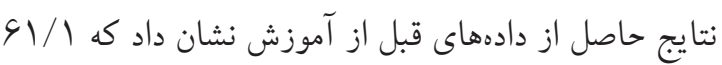

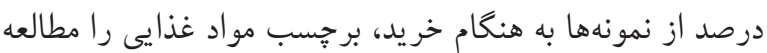

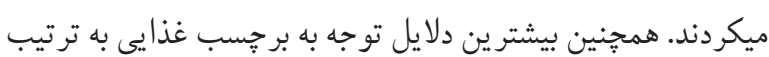

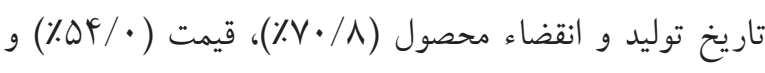

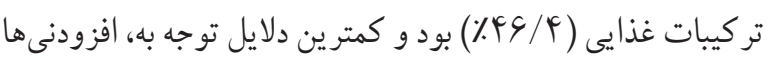

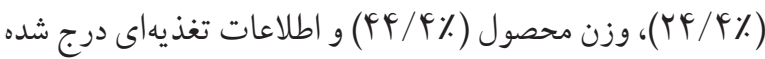

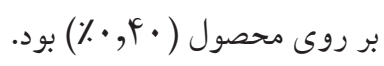

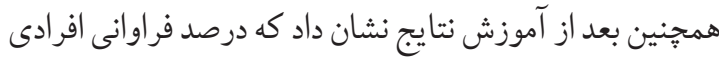

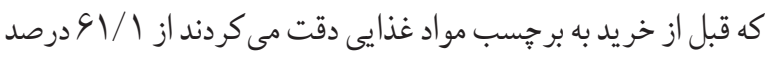

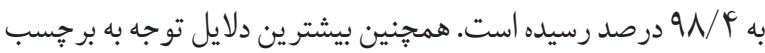

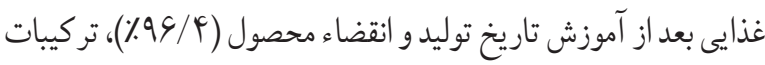

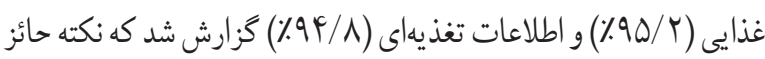

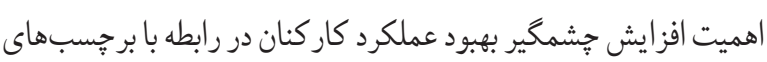
غذايى نسبت به قبل از آموزش است (نمودار شماره ل) ).

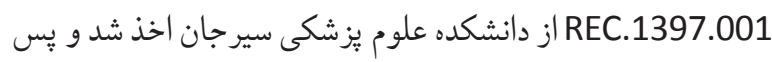
از كسب مجوزهاى لازم از مسئولين دانشكده به واحدهاى مورد نظر مراجعه كَرديده و بعد از تبيين اهداف يُزوهش، بِ برسشنامه در اختيار

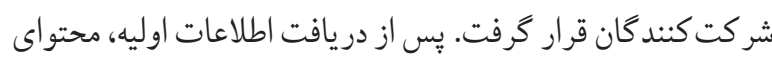

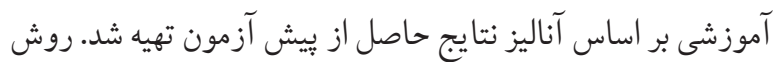

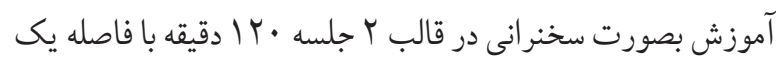

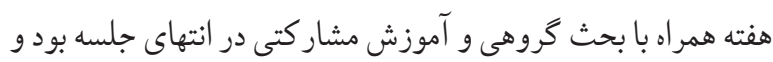

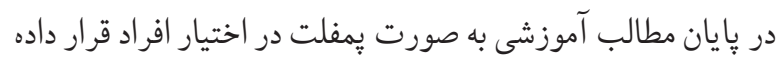

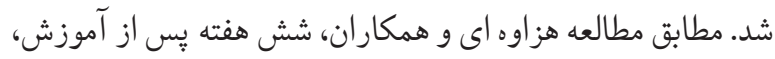

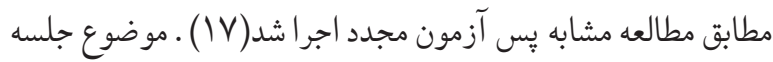

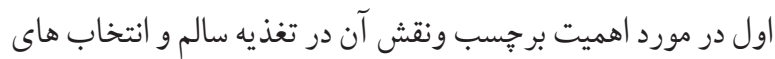
غذايى مناسب و اجزاى برجسب و جلسه دوم در مورد درك و تفسير

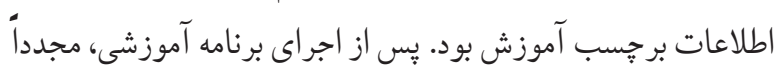
ير سشنامها توسط افراد مورد مطالعه تكميل شد.

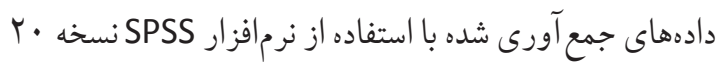

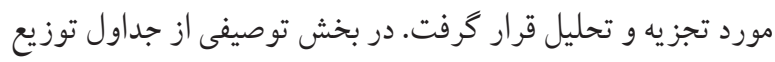

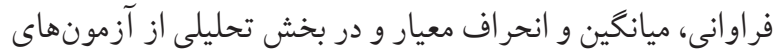

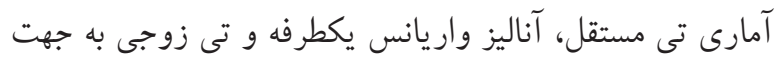

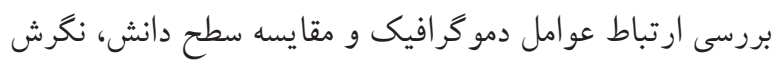
و عملكرد قبل و بعد از آموزش استفاده كرديد.

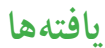
در اين مطالعه ••آنفر از افراد شاغل در معاونتهاى مختلف (درمان، بهداشت، آموزش، دانشجويى و توسعه) مورد بررسى قرار كرففتند. محدوده

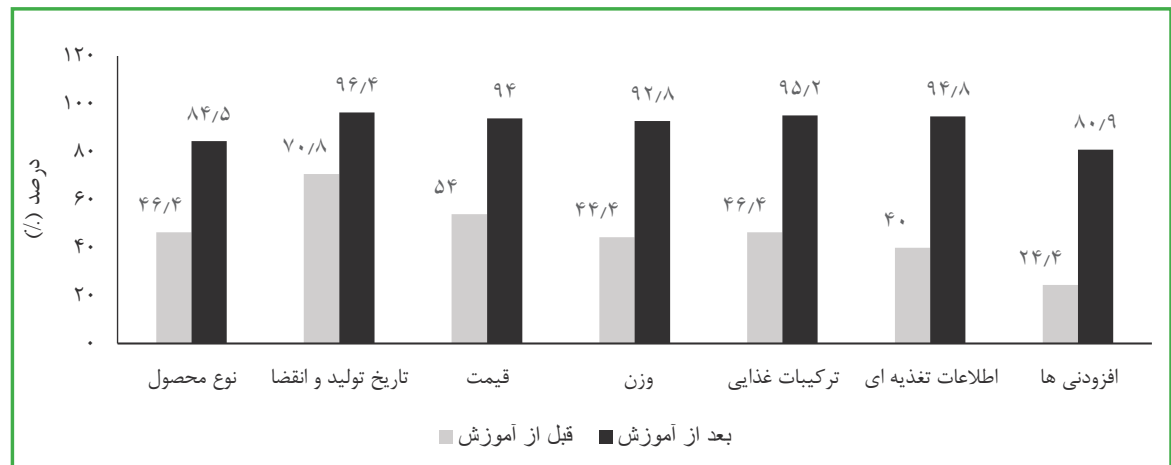

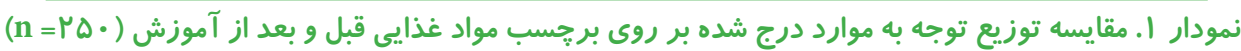




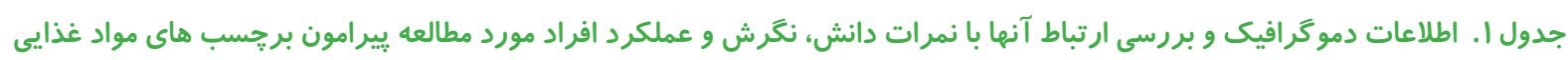
$(\mathbf{n}=r \Delta \cdot)$

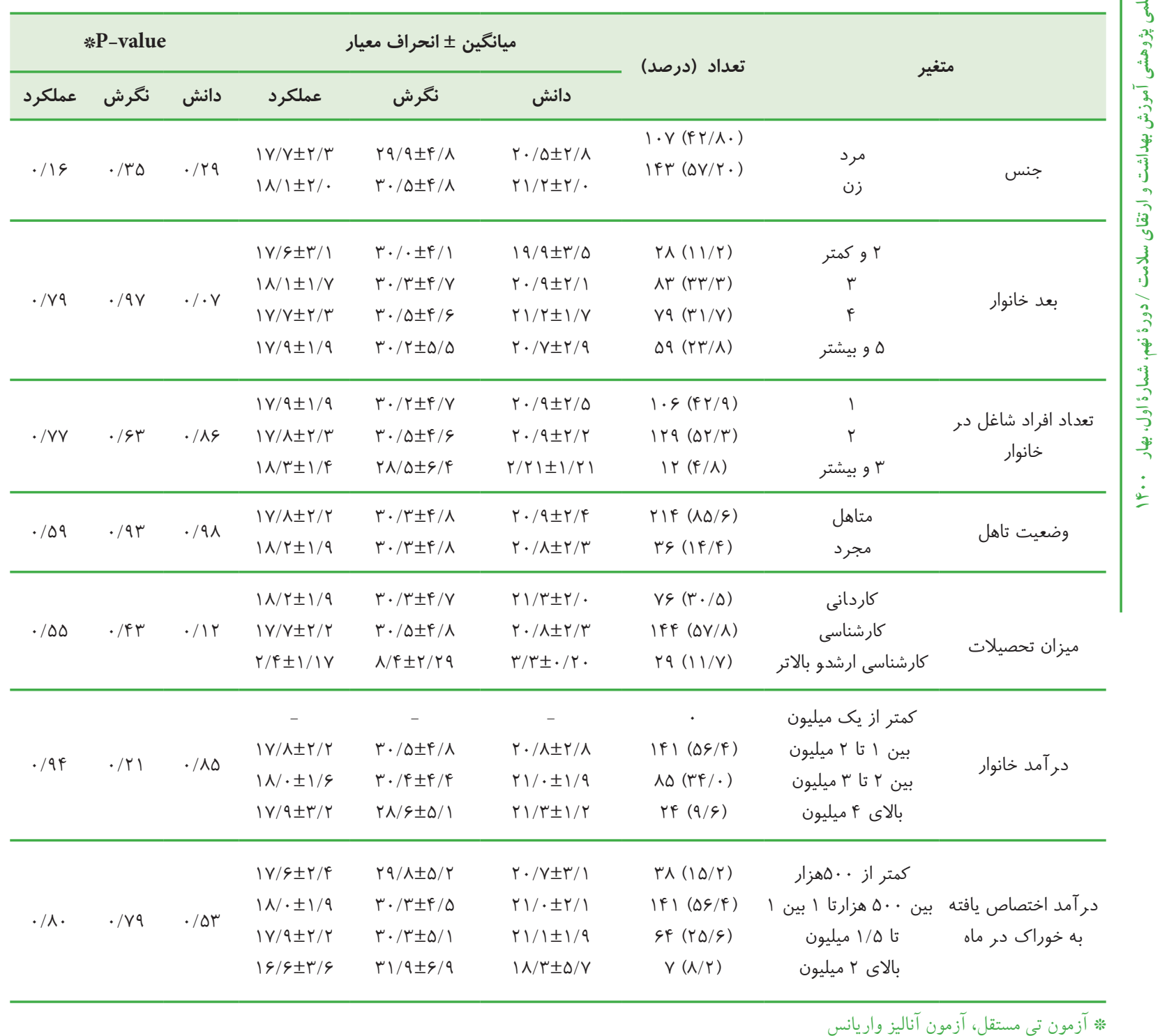

تنها أ نفر از شركت كنندگان حتى بعد از آموزش در موقع از آموزش بيانكر تفاوت آشكار اعداد بدست آمده مىباشند. بطور

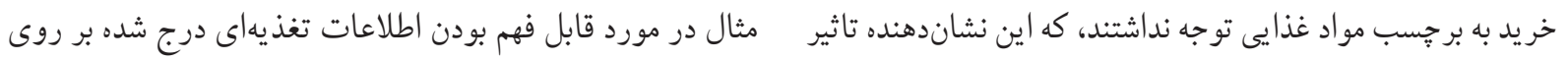

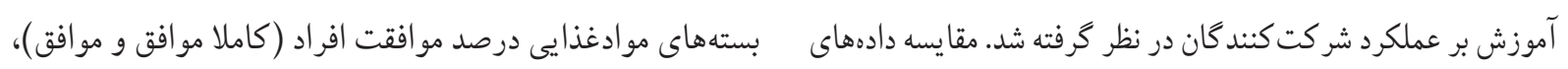

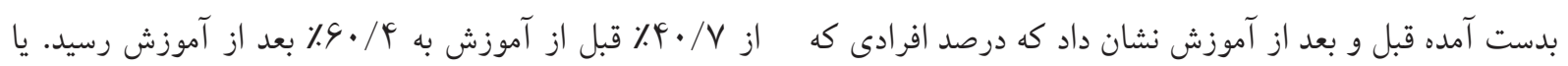

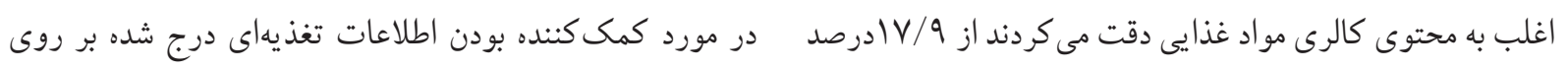

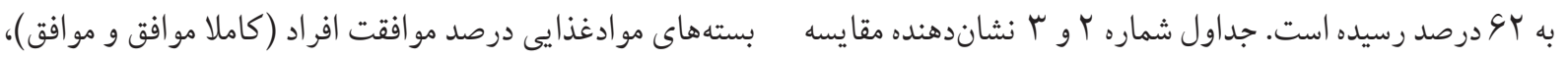

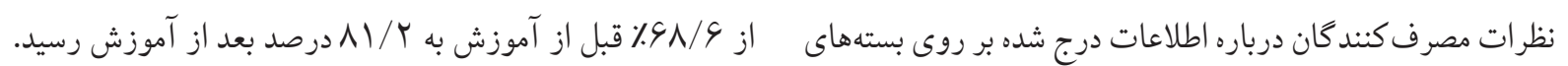

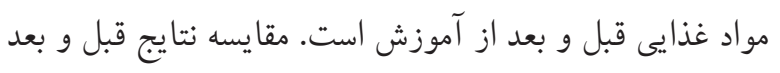


جدول r. توزيع نظرات مصرف كنند گَان بر اساس اطلاعات درج شده بر روى بستههاى مواد غذايى قبل از آموزش ( • n =ro)

\begin{tabular}{|c|c|c|c|c|c|}
\hline تعدادلا مخالفم (درصد) & تعداد (درصد) & تظداد (درصدار) & تعداد (درصد) & تعداد (درصلا موافقم) & سوال \\
\hline$\Delta(1 / \Lambda)$ & $q \vee(r F / G)$ & $r(1 / 1)$ & $1.9($ ( $N / 9)$ & rG (Ir/q) & تاريخ توليد وانقضاء درج شده بر روانا است بسته هاى مواد \\
\hline $1 \cdot(r / \varphi)$ & $\| \mu(\boldsymbol{f} \cdot / \boldsymbol{f})$ & $\operatorname{IV}(c / 1)$ & $9 \varphi(\mu r / \mu)$ & $\operatorname{lf}(\Delta / \cdot)$ & تاريخ توليد وانقضاء بسته هاى مواد غذايى در محل مناسبى \\
\hline $\operatorname{IV}(s / 1)$ & $1 \cdot r(r \varsigma / \varphi)$ & $r \Delta(\Lambda / q)$ & $q r(r r / q)$ & $\operatorname{lf}(\Delta / \cdot)$ & اطلاعات تغذيه اى درج شده بر روى بسته هاى موادغذايى \\
\hline $1 \cdot(r / \varphi)$ & $q \vee(\mu F / s)$ & $S \Delta(r \mu / r)$ & SG (TH/G) & $\mid r(\boldsymbol{F} / \tilde{\mu})$ & اطلاعات تغذيه اى درج شده بر روى بسته هاى موادغذايى \\
\hline $1(\cdot / \mathbb{f})$ & $q \vee(\mu F / G)$ & $r q(1 r / q)$ & $1 \cdots(r \Delta / V)$ & 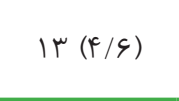 & 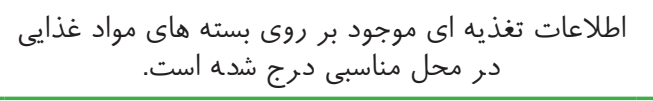 \\
\hline $1(\cdot / \mathcal{F})$ & $\operatorname{IV}(c / 1)$ & $r(\Lambda / r)$ & $V \Delta(r s / \Lambda)$ & $\operatorname{lrF}(\mathcal{F} V / q)$ & برجسب هاى مواد غذايى براى مصرف كنندگان بسيار مفيدند. \\
\hline$r(\cdot / V)$ & $V \Delta(r \varsigma / \Lambda)$ & $V Y(Y V / D)$ & $V^{F}(r G / F)$ & $1 \wedge(s / F)$ & اطلاعات تغذيه درج شده دبر روى بر جسب هاى مواد \\
\hline$G(Y / I)$ & $q \wedge(r \Delta / \cdot)$ & $r V(I r / r)$ & $q \cdot(r r / l)$ & $19(5 / 1)$ & مطالب درج شده بر روى برجسب هاى مواد غذايى به هـته \\
\hline $\operatorname{lr}(\boldsymbol{F} / \mu)$ & $19(8 / 1)$ & $r V(9 / 9)$ & $\operatorname{lmp}(\mathcal{F} V / q)$ & $\Delta \wedge(r \cdot /\rangle)$ & 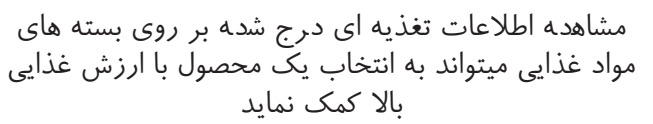 \\
\hline
\end{tabular}

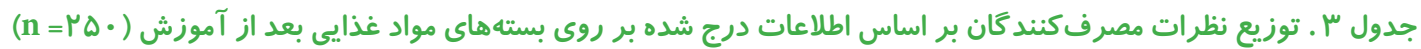

\begin{tabular}{|c|c|c|c|c|c|c|}
\hline 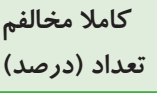 & 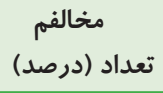 & تعداد (درصد ندارم) & ت معداد (درصد) & تعداد (درصدالا موافقم) & سوال & \\
\hline$r(\cdot / \Lambda)$ & $\mid r \cdot(\Delta r / \cdot)$ & $\Delta(Y / \cdot)$ & $V \backslash(Y \Lambda / F)$ & $\operatorname{Fr}(\mid s / \Lambda)$ & تاريخ توليد وانقضاء درج شده بر روانا است بسته هاى مواد & 1 \\
\hline $9(\mu / \varphi)$ & $|f|(\Delta G / F)$ & $r \mid(\Lambda / r)$ & $G \Lambda(Y V / r)$ & $\|(\mathbb{F} / \mathbb{F})$ & تاريخ توليد وانقضاء بسته هاى مواد غذايى در محل مناسبى & r \\
\hline $\operatorname{Ir}(\boldsymbol{F} / \Lambda)$ & $\mathbb{I r} \cdot(\boldsymbol{F} \wedge / \cdot)$ & $r q(11 / 4)$ & $V \wedge(\Psi \backslash / Y)$ & $\|(\mathbb{F} / \mathcal{F})$ & اطلاعات تغذيه اى درج شده بر روى بسته هاى موادغذايى & r \\
\hline$r(1 / r)$ & $\operatorname{Irr}(\Delta r / \Lambda)$ & $F \Psi(\mid V / r)$ & $G \mid(Y F / F)$ & $\|(\mathcal{F} / \mathcal{F})$ & اطلاعات تغذيه اى درج شده بر روى بسته هاى موادغذايى & 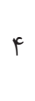 \\
\hline$\cdot(\cdot)$ & $\operatorname{lr\Delta }(\Delta \cdot / \cdot)$ & $r V(1 \cdot / \Lambda)$ & $q \cdot(r c / \cdot)$ & $\wedge(r / r)$ & 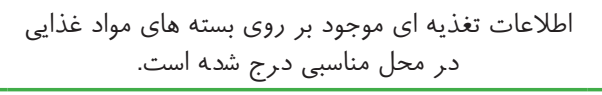 & $\Delta$ \\
\hline$\cdot(\cdot)$ & $G(Y / F)$ & $r(1 / r)$ & $S O(r G / \cdot)$ & $\operatorname{IV} s(V \cdot / F)$ & برجسب هاى مواد غذايى براى مصرف كنديدان بسيار & 4 \\
\hline$\cdot(\cdot)$ & r $(1 \Delta / r)$ & $\mu F(\mid r / G)$ & $\| V(\& \varepsilon / \Lambda)$ & $\Delta Q(K r / G)$ & اطلاعات تغذيه درج شده بر روى برجسب هاى مواد غذايى & $\checkmark$ \\
\hline$f(1 / 9)$ & $G \wedge(Y Y / Y)$ & $r V(1 \cdot / \Lambda)$ & $\| r(F F / \Lambda)$ & rq (1ه/s) & مطالب درج شده بر روى برحسب هاى مواد غذايى به هـته & $\wedge$ \\
\hline$r(1 / r)$ & $r \wedge(\mid 1 / r)$ & $1 S(S / F)$ & $q \mathcal{F}(\Psi V / \varphi)$ & $1.9(\&+/ \varepsilon)$ & 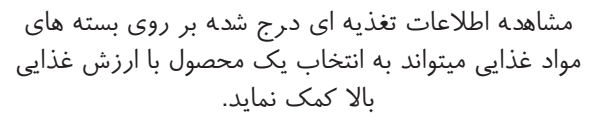 & 9 \\
\hline
\end{tabular}


بيانكر تفاوت آشكار اعداد بدست آمده مىباشند. جهت مقايسه سطح

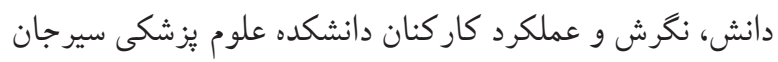
از آزمون آمارى تى زوجى استفاده شد.
جدول شماره F نشاندهنده مقايسه پِاسخ شركت كنند سو الات نمونه جدول حقايق تغذيهاى درج شده بر روى يرسشنامه

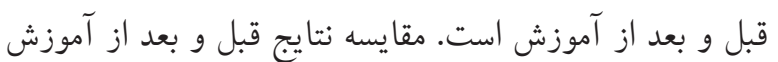

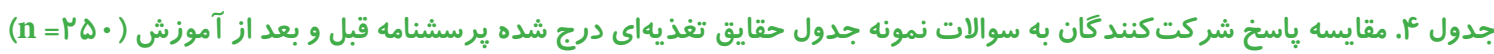

\begin{tabular}{|c|c|c|}
\hline \multicolumn{2}{|c|}{ 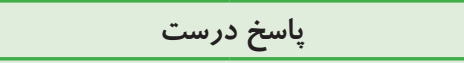 } & \multirow[b]{2}{*}{ 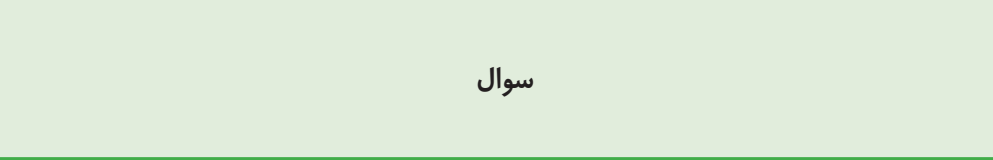 } \\
\hline 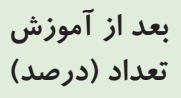 & 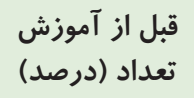 & \\
\hline$r \mu q(q \Delta / 9)$ & $\operatorname{IVr}(\varepsilon \mid / F)$ & جند وعده (سروينگ) شير در بسته وجود دارد؟ \\
\hline$r F V(q \Lambda / \Lambda)$ & $r \cdot r(V r / l)$ & جند كالرى در هر وعده (سروينگ) شير وجود دارد؟ \\
\hline YFV $(9 \Lambda / \Lambda)$ & $190(0 N / 9)$ & هند درصد از ميزان توصيه شده روزانه كلسيم از هر وعده (سروينگ) شير بدست مى آيد؟ \\
\hline rFq (৭9/4) & $199(\mathrm{~V} / 1)$ & جند گرم يروتئين در هر وعده (سروينگ) شير وجود دارد؟ \\
\hline $\operatorname{rer}(9 s / \Lambda)$ & $19 \cdot(\Delta V / 1)$ & جند ميلى گرم كلسترول در هر وعده (سروينگ) شير وجود دارد؟ \\
\hline$r F \cdot(94 / \cdot)$ & $11 \wedge(F r / 1)$ & קند درصد از ميزان توصيه شده روزانه كربوهيدرات از هر وعده (سروينك) شير بدست \\
\hline
\end{tabular}

سيرجان در خصوص برجسب هاى مواد غذايى بوده و بيشترين تاثير بر روى متغير آكاهى و عملكرد مشاهده شد.

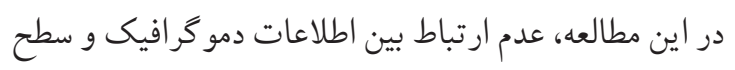
آكاهى، نكرش و عملكر دكار كنان مشاهده شد. درحاليكه مطالعات

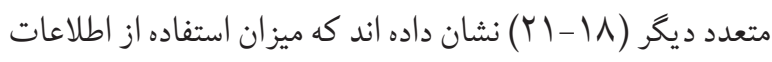
تغذيه اى و درك مطالب برجبسب هاى مواد غذايى با اطلاعات جمعيت شناسى بو يزه مر تبه اجتماعى، سن، جنس، و داشتن فرزندان

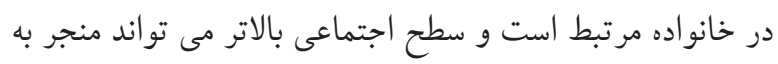

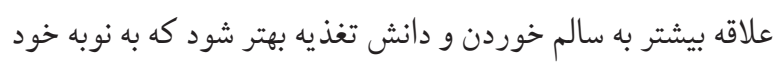
بر استفاده و درك اطلاعات مربوط به تغذيه، تاثير مى كذارد. اما

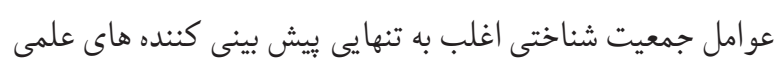

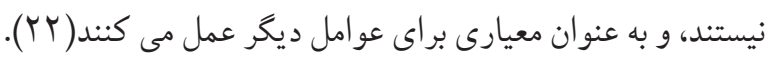
يافته هاى مطالعه حاضر نشان داد كه دانش تغذيه اي بيرامون

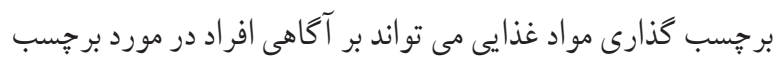

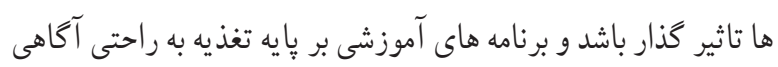

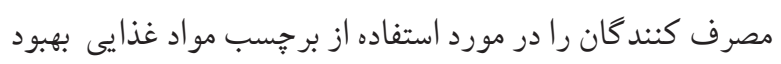

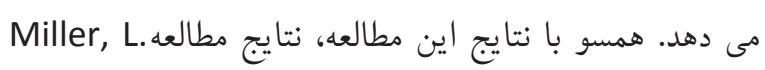
M. S., \& Cassady, D. L
جدول شماره ه ميانگين و انحر اف معيار نمرات دانش، نكرش

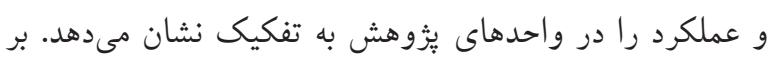

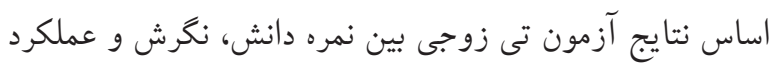

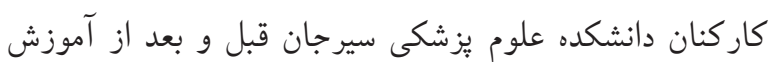

$$
\text { اختلاف معنى دارى وجود دارد (ه •, • P (P). }
$$

جدول ه. مقايسه ميانگين و انحراف معيار نمرات آكاهى، نغرش

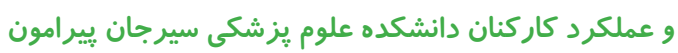

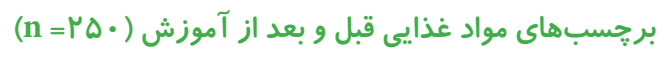

\begin{tabular}{|c|c|c|c|}
\hline *⿻-value & (ميانكين \ انحراف معيار) & 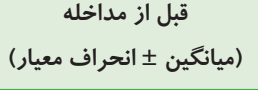 & متغير \\
\hline$<\cdot / \cdot \cdot 1$ & $r / F r \pm r \cdot / 9 r$ & $11 / r \wedge \pm r / r \Lambda$ & آكاهى \\
\hline.$/ . \mu p$ & $r / \vee q \pm r \cdot / r 1$ & $\Delta / \kappa^{\mu} \pm r q / F \wedge$ & 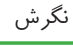 \\
\hline$<\cdot / \cdot \cdot 1$ & $r / / \Delta \pm I V / \Lambda \Lambda$ & $r / \Gamma| \pm| r / G r$ & عملكرد - ع م \\
\hline
\end{tabular}
مطالعه حاضر با هدف بررسى تاثير آموزش بر دانش، نكرش و عملكرد

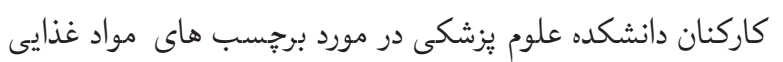

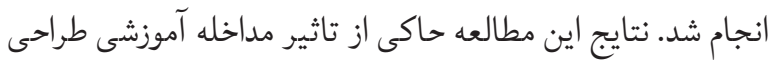

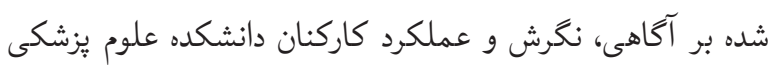


خصوص برجسبهاى مواد غذايى دارد. بنابراين برنامه آموزشى كه

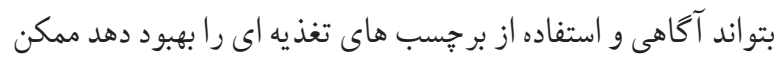

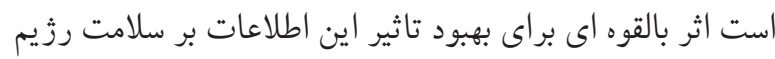

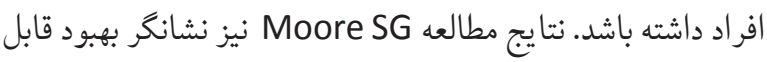
توجه در درك و آكاهى شر كت كنند كان و همجينين عملكرد آنان آنان

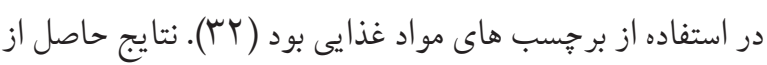

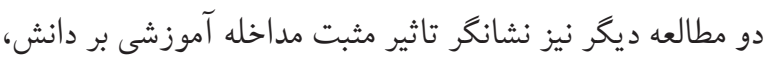

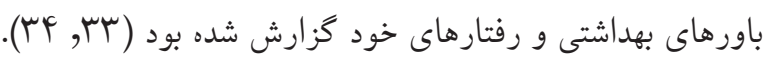

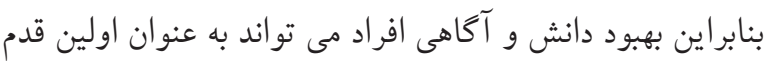

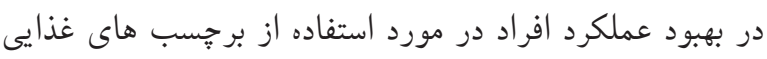

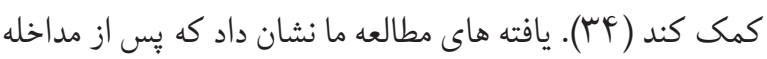

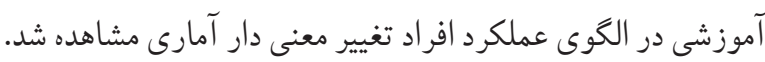

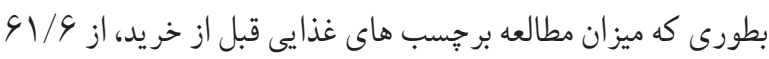

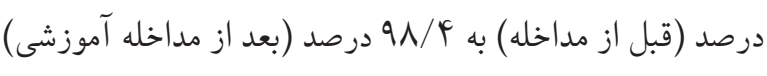

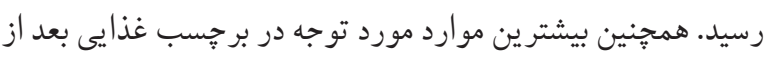

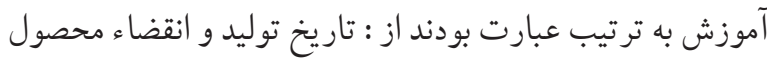

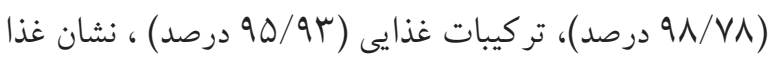

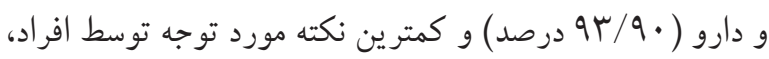

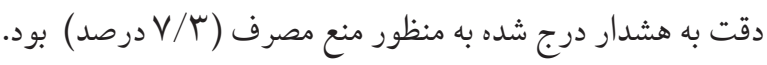

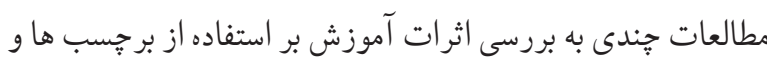

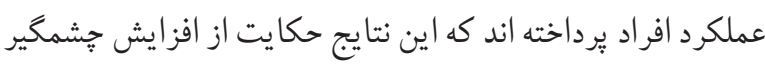

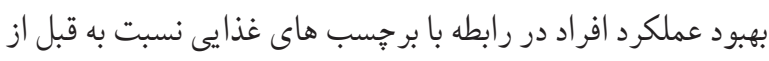

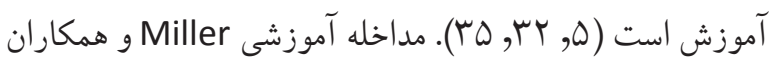

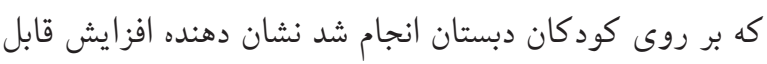

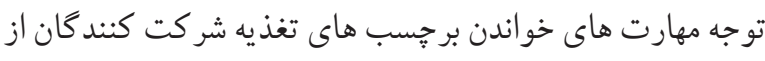

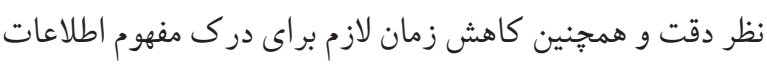

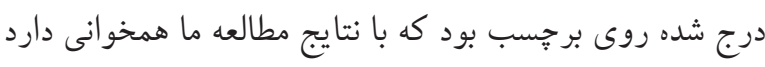

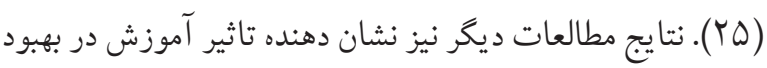

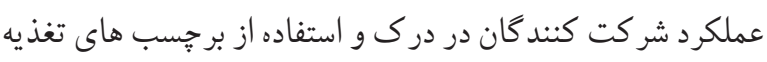

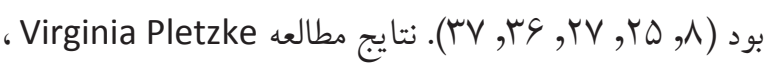
با بررسى آموزش الكوهاى خريد مواد غذايى نشان داد كه شركت
تغذيه اى بر استفاده از برجسب مواد غذايى و تصميم كيرى در

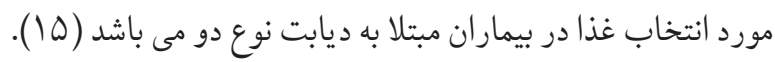

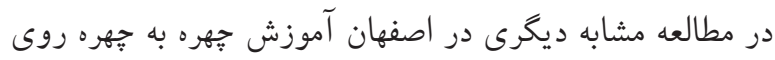

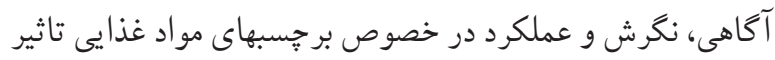

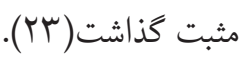

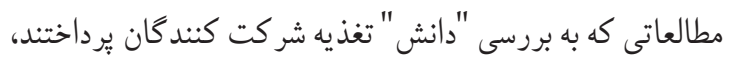

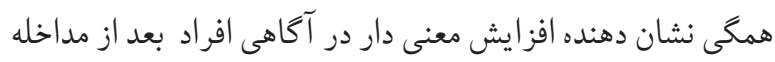

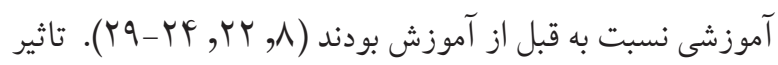

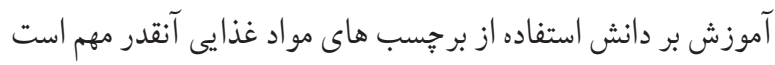

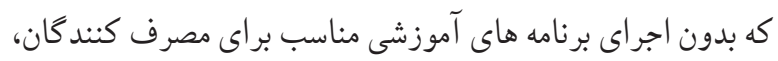

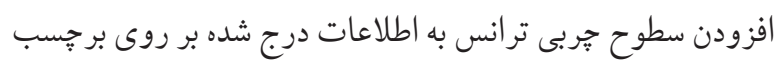

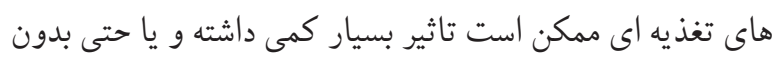

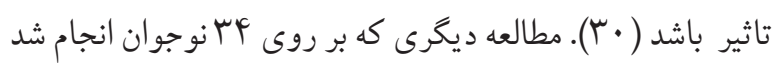

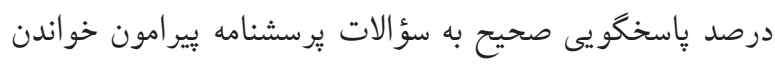

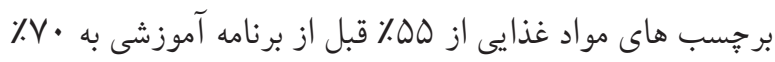

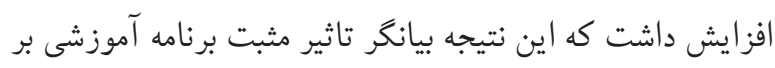

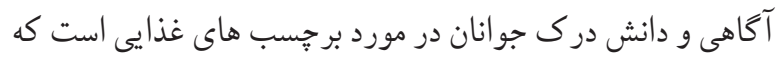

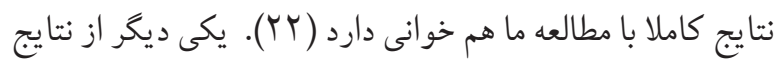

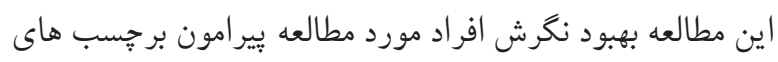

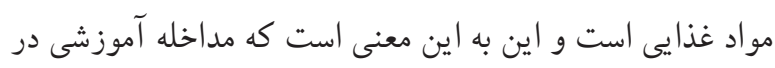

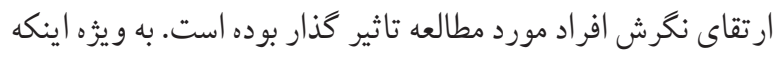

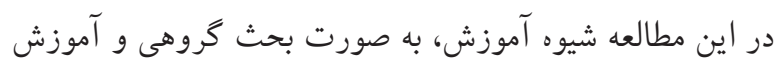

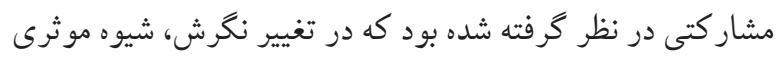

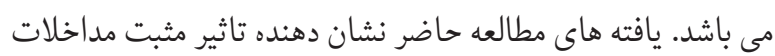

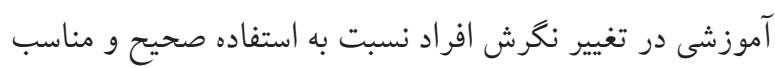

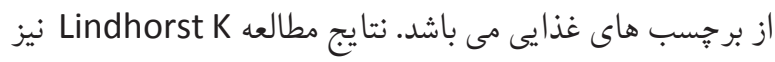
نشان داد فراهم آوردن كار كاه هاى آموزشى حضورى در مناطق

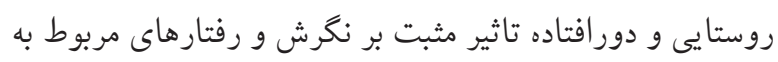

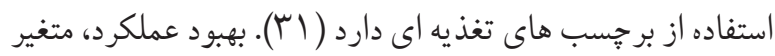
ديكرى است كه در اين مطالعه مورد بررسى قرار كرفت و و نتائيج نشان داد كه آموزش تاثير جشمخيرى بر بهبود عملكرد افراد در 
ارتباطند درجهت كاهش ابتلا به بيماريهاى تغذيه اي ضرورى است. از جمله نقاط قوت مطالعه حاضر مداخله روى افزايش انتخاب هاى سالم غذايى است.از محدوديت هاى مهم مطالعه ما ميتوان به عدم وجود كروه كنترل جهت مقايسه نتايج اشاره نمود. از ديخر محدوديت هاى اين مطالعه شامل ماهيت مقطعى بودن نتيجه كيرى ها درباره عليت است. همجنين، تمام داده ها از خود گزارش دهى بدست آمده كه مى تواند در معرض هر گونه تعصب تصادفى و سيستماتيكى و كزارش دهى بيش از حد قرار بكيرد.همجنين با توجه به محل كار مشاركت كنندگان در دانشكده يزشكى، احتمالا آموزش تاثير بيشترى روى اين افراد با تحصيلات رشته هاى علوم يزشكى دارد. تشكر و قدردانى

نغارندگان بدينوسيله مراتب سياس و قدردانى خود را از رياست محترم و معاونت محترم يثوهشى دانشكده علوم يزشكى سيرجان به دليل حمايت از اين تحقيق، و كليه يرسشگران و افراد محترم شركت كننده در اين طرح يثوهشى كه با همكارى خود، جمع آورى داده ها و انجام اين مطالعه را ممكن ساختند، ابراز مى دارند. تعارض منافع بدينوسيله نويسندكان اعلام مى كنند كه اين اثر حاصل يك يزوهش مستقل بوده و هيجگگ ديگرى ندارد.

\section{References}

1. Viola GC, Bianchi F, Croce E, Ceretti E. Are food labels effective as a means of health prevention? Journal of public health research, 2016. Dec 9;5(3). 768. https://doi.org/10.4081/jphr.2016.768 PMid:28083524 PMCid:PMC5206777

2. Ghoreishi M-S, Vahedian-Shahroodi M, Jafari A, Tehranid $H$. Self-care behaviors in patients with type 2 diabetes: Education intervention base on social cognitive theory. Diabetes \& Metabolic Syndrome: Clinical Research \& Reviews. 2019;13(3):2049-56. https://doi.org/10.1016/j.dsx.2019.04.045 PMid:31235135

3. Rahmdel, Farahbod B, Mazloomi SM, Sagheb MM, Babajafari S, Abdollahzadeh SM . Dietary intake of phosphorous and protein in Shiraz, Iran: A comparison of three assessment methods. Journal of Food
كنند گان درصد كمترى از مواد غذايى حاوى اسيدهاى جرب ترانس را خريدارى كردند و اين بهبود عملكرد ناشى از جلسات آموزش تغذيه بر گزار شده است كه مى تواند الخوهاى خر يد مواد غذايى را رتقا دهد (YN). در قسمتى ديخر از مطالعه از شركت كنند خواسته شد تا با مشاهده نمونه برجسب غذايى درج شده بر روى يرسشنامه و تفسير اطلاعات درج شده به سوالات مربوطه پِاسخ دهند. كمترين ياسخ درست به ترتيب مربوط به محاسبه درصد از ميزان توصيه شده روزانه كربوهيدرات از هر وعده (سروينگ) شير با //F أ درصد ياسخ دهى صحيح و محاسبه درصد از ميزان

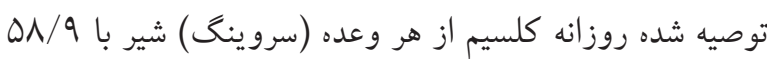
درصد مى باشد. يافته اخير بيانكر اين واقعيت است كه بيش از نيمى از شركت كنند كان با تخمين و تفسير صحيح مقادير درج شده مشكل دارند. ياسخ به سوالات نمونه بر خسب بعد از بر گزارى دوره

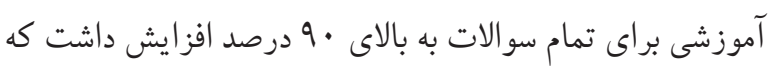
اين صعود جشمخير نشانگر نقش مهم آموزش در استفاده مناسب نتيجه، كيرى جـب هاى مو اد غذايى مى باشد. باتوجه به اثربخش بودن برنامه آموزشى اجراشده، اجراى برنامه هاى آموزش تغذيه سالم نحوه استفاده از برجسب مواد غذايى اهميت استفاده از برجسب هاى درج شده براى كاركنان سيستم بهداشتى

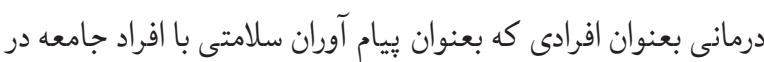

Composition and Analysis, 2017. 1 62: 177-183. https://doi.org/10.1016/j.jfca.2017.05.012

4. Andervazh L, jalili s, zanjani s. Studying the Factors Affecting the Attitude and Intention of Buying Organic food consumers: structural equation model. Iranian Journal of Health Education and Health Promotion. 2020;8(1):35-44. https://doi.org/10.29252/ijhehp.8.1.35

5. Hoseini R, Hoseini Z. Investigating Nutritional Literacy of Male Student Athletes Contributed in 2018 Iran University Games. Journal of Health Literacy. 2019;4(1):53-9.

6. Azman, N. and S.Z. Sahak, Nutritional label and consumer buying decision: a preliminary review. ProcediaSocial and Behavioral Sciences, 2014. 130: 490-498. https://doi.org/10.1016/j.sbspro.2014.04.057

7. Ahmadi, A. Torkamani P, Sohrabi Z, Ghahremani F. Nutrition knowledge: application and perception of food labels 
among women. Pak J Biol Sci, 2013. 16(24): 2026-2030. https://doi.org/10.3923/pjbs.2013.2026.2030 PMid:24517023

8. Lewis, JE, Arheart KL, LeBlanc WG, Fleming LE, Lee DJ, Davila EP, et al. Food label use and awareness of nutritional information and recommendations among persons with chronic disease-. The American journal of clinical nutrition, 2009. 90(5): 1351-1357. https://doi.org/10.3945/ajcn.2009.27684 PMid:19776144 PMCid:PMC3151015

9. Madilo FK, Owusu-Kwarteng J, Kunadu AP, TanoDebrah K. Self-reported use and understanding of food label information among tertiary education students in Ghana. Food Control, 2020. 108: 106841. https://doi.org/10.1016/j.foodcont.2019.106841

10. Todua, N. Influence of Food Labeling Awareness on healthy behavior of Georgian Consumers. EcoForum, 2017. 6(2): 1-17.

11. Esfandiari Z, Marasi MR, Estaki F, Sanati V, Panahi E, Akbari $\mathrm{N}$, et al. Influence of education on knowledge, attitude and practices of students of Isfahan University of Medical Sciences to traffic light inserted on food labeling. Tehran University Medical Journal, 2019. 77(1): 54-62.

12. Verduin, P., S. Agarwal, and S. Waltman, Solutions to obesity: perspectives from the food industry-. The American journal of clinical nutrition, 2005. 82(1): p. 259S-261S. https://doi.org/10.1093/ajcn.82.1.259S

13. Campos, S., J. Doxey, and D. Hammond, Nutrition labels on pre-packaged foods: a systematic review. Public health nutrition, 2011. 14(8): 1496-1506. https://doi.org/10.1017/S1368980010003290 PMid:21241532

14. Limbu, Y.B., et al., Nutritional knowledge, attitude, and use of food labels among Indian adults with multiple chronic conditions. British Food Journal, 2019. https://doi.org/10.1108/BFJ-09-2018-0568

15. Miller, L.M.S. and D.L. Cassady, The effects of nutrition knowledge on food label use. A review of the literature. Appetite, 2015. 92: 207-216. https://doi.org/10.1016/j.appet.2015.05.029 PMid:26025086 PMCid:PMC4499482

16. Moore, S.G., et al., Effect of educational interventions on understanding and use of nutrition labels: A systematic review. Nutrients, 2018. 10(10): 1432. https: / / d o i.org/10.3390/nu10101432 PMid:30287766 PMCid:PMC6213388

17. Hazavehei M M, Faghih Solaimani P, Moeini B, Soltanian A R. Evaluation of the Educational Nutrition Intervention's Effects on Healthy Nutritional Behaviors Promotion in Elderly of Sanandaj: Application BASNEF Model. J Neyshabur Univ Med Sci. 2017; 5 (1) :39-51

18. Satia, J.A., J.A. Galanko, and M.L. Neuhouser, Food nutrition label use is associated with demographic, behavioral, and psychosocial factors and dietary intake among African Americans in North Carolina. Journal of the American Dietetic Association, 2005. 105(3): 392-402. https://doi.org/10.1016/j.jada.2004.12.006 PMid:15746826

19. Carrillo, E., P. Varela, and S. Fiszman, Influence of nutritional knowledge on the use and interpretation of Spanish nutritional food labels. Journal of food science, 2012. 77(1): H1-H8. https://doi.org/10.1111/j.1750-3841.2011.02479.x PMid:22132819

20. Harbor-Locure, A.L., P.E. McLean-Meyinsse, and V.V. Bethea, Label use and importance rankings for selected milk labeling attributes. Journal of Food Distribution Research, 2001. 32(3): 54-68.

21. Guthrie JF, Fox JJ, Cleveland LE, Welsh S. Who uses nutrition labeling, and whateffects doeslabeluse haveondietquality? Journal of Nutrition education, 1995. 27(4): 163-172. https://doi.org/10.1016/S0022-3182(12)80422-5

22. Hawthorne KM, Moreland K, Griffin IJ, Abrams SA. An educational program enhances food label understanding of young adolescents. Journal of the American Dietetic Association, 2006. 106(6): 913-916. https://doi.org/10.1016/j.jada.2006.03.004 PMid:16720132

23. Esfandiari Z, Mirlohi M, Tanha JM, Hadian M, Mossavi SI, Ansariyan A, et al. Effect of Face-to-Face Education on Knowledge, Attitudes, and Practices Toward "Traffic Light" Food Labeling in Isfahan Society, Iran. International Quarterly of Community Health Education, 2020: 0272684X20916612. https://doi.org/10.1177/0272684X20916612 PMid:32252587

24. Jacobs, S.A., H. de Beer, and M. Larney, Adult consumers' understanding and use of information on food labels: a study among consumers living in the Potchefstroom and Klerksdorp regions, South Africa. Public health nutrition, 2011. 14(3): 510-522. https://doi.org/10.1017/S1368980010002430 PMid:20939940

25. Miller LM, Beckett LA, Bergman JJ, Wilson MD, Applegate EA, Gibson TN. Developing nutrition label reading skills: a web-based practice approach. Journal of medical Internet research, 2017. 19(1):e16. htt ps://doi .org/10.2196/jmir.6583 PMid:28087497 PMCid:PMC5273399

26. Macon JF, Oakland MJ, Jensen HH, Kissack PA.Food label use by older Americans: data from the Continuing Survey of Food Intakes by Individuals and the Diet and Health Knowledge Survey 1994-96. Journal of Nutrition for the Elderly, 2004. 24(1): 35-52. 
https://doi.org/10.1300/J052v24n01_03 PMid:15339719

27. Mahdavi, A.M., P. Abdolahi, and R. Mahdavi, Knowledge, attitude and practice between medical and non-medical sciences students about food labeling. Health promotion perspectives, 2012. 2(2): $\mathrm{p} 173$.

28. Katz DL, Treu JA, Ayettey RG, Kavak Y, Katz CS, Njike V. Peer Reviewed: Testing the Effectiveness of an Abbreviated Version of the Nutrition Detectives Program. Preventing chronic disease, 2014. 11. https://doi.org/10.5888/pcd11.130161 PMid:24721217 PMCid:PMC3984941

29. Kim, N.-Y. and J.-S. Lee, A study on perception and utilization of food-nutrition labeling by age in Busan residents. Journal of the Korean Society of Food Science and Nutrition, 2009. 38(12): 1801-1810. https://doi.org/10.3746/jkfn.2009.38.12.1801

30. Howlett, E., S. Burton, and J. Kozup, How modification of the nutrition facts panel influences consumers at risk for heart disease: the case of trans fat. Journal of Public Policy \& Marketing, 2008. 27(1): 83-97. https://doi.org/10.1509/jppm.27.1.83

31. Lindhorst K, Corby L, Roberts S, Zeiler S. Rural consumers' attitudes: towards nutrition labelling. Canadian Journal of Dietetic Practice and Research, 2007. 68(3): 146-149. https://doi.org/10.3148/68.3.2007.146 PMid:17784974

32. Moore, S., et al., Effect of Educational Interventions on Understanding and Use of Nutrition Labels: A Systematic Review. Nutrients, 2018. 10(10): 1432. https: / / doi.org / $10.3390 /$ nu 10101432 PMid:30287766 PMCid:PMC6213388
33. Pettigrew, S., et al., Evaluation outcomes of a longrunning adult nutrition education programme. Public health nutrition, 2016. 19(4): 743-752. https://doi.org/10.1017/S1368980015001536 PMid:25990547

34. Chapman-Novakofski, K. and J. Karduck, Improvement in knowledge, social cognitive theory variables, and movement through stages of change after a communitybased diabetes education program. Journal of the American Dietetic Association, 2005. 105(10): p. 1613-1616. https://doi.org/10.1016/j.jada.2005.07.010 PMid:16183364

35. SEE risk briefing Obesity concerns in the food and beverage industry, Ethical Investment Research Services (EIRIS)

36. Kollannoor-Samuel, G., et al., Effects of food label use on diet quality and glycemic control among Latinos with type 2 diabetes in a community health worker-supported intervention. American journal of public health, 2016. 106(6): 1059-1066. https://doi.org/10.2105/AJPH.2016.303091 PMid:27077337 PMCid:PMC4880245

37. Pennings, M.C., T. Striano, and S. Oliverio, A picture tells a thousand words: Impact of an educational nutrition booklet on nutrition label gazing. Marketing Letters, 2014. 25(4): 355-360. https://doi.org/10.1007/s11002-013-9259-9

38. Pletzke V, Henry BW, Ozier AD, Umoren J. The effect of nutrition education on knowledge, attitude, and behavior relating to trans fatty acids in foods. Family and Consumer Sciences Research Journal, 2010. 39(2): 173-183. https://doi.org/10.1111/j.1552-3934.2010.02055.x 